\title{
Large wood recruitment and mobility in steep mountain streams of contrast European landscapes
}

\author{
Tomáš Galia ${ }^{1, *}$, Václav Škarpich ${ }^{1}$, and Radek Tichavský ${ }^{1}$ \\ ${ }^{1}$ Ostrava University, Department of Physical Geography and Geoeceology, Ostrava, Czech Republic
}

\begin{abstract}
We present a comparative study of large wood (LW) mobility in two steep channels $(0.06<S<0.20)$ of contrast European landscapes during major hydro-geomorphic events of similar magnitude. We investigated a headwater perennial stream draining Central European medium-high mountain relief (the Klepáčský, Hrubý Jeseník Mts, Czech Republic; $A \leq 2.5 \mathrm{~km}^{2}$ ) and an ephemeral Mediterranean steep stream (the Sfakiano Gorge, Crete, Greece; $A \leq 52 \mathrm{~km}^{2}$ ). Both studied hydro-geomorphic events were partially accompanied by debris-flood or debris-flow character of sediment transport including significant content of LW. The minimal estimations of transported LW volume were $71.3 \mathrm{~m}^{3}$ along $1.7 \mathrm{~km}$ long reach in the Klepáčský and $49.4 \mathrm{~m}^{3}$ along $4 \mathrm{~km}$ long reach in the Sfakiano Gorge. Despite completely different characters of hydrologic regimes, riparian zones and valley confinement settings, living trees in the valley floor played crucial role in wood deposition and development of large jams in both environments. The trees living in the valley floor were the main source of LW in the studied Mediterranean channel, whereas long-term LW recruitment from very steep hillslopes or rock cliffs was quite negligible. On the other hand, previous windstorms in the Klepáčsky caused notable delivery of LW from adjacent hillslopes and LW recruitment by bank erosion occurred only at spatially-limited semiconfined parts of the valley.
\end{abstract}

\section{Introduction}

Large wood (LW) is an important geomorphic and ecological component of the fluvial landscape, including steep mountain channels (here defined as $S>0.04 \mathrm{~m} / \mathrm{m}$ ). Several aspects of LW recruitment, transport and deposition in steep channels are still not completely understood, when especially field data about LW mobility thresholds and volumes during major flood events are still scarce (but see $[1,2,3]$ ). Fluvial transport of instream wood is mostly dependent upon ratios between LW length and channel width and between LW diameter and flow depth $[4,5]$. The channel width of steep headwater streams is usually much smaller than the typical height of trees living in the valley corridor. Thus LW is assumed to be transport-limited by ordinary flows when compared to wider lowland rivers $[6,7]$. In this way, debris flows and debris floods represent irreplaceable LW

\footnotetext{
* Corresponding author: tomas.galia@,osu.cz
} 
recruitment and transport agents in mountainous landscapes, because they are usually able to evacuate all of the material within a valley fill, including large boulders and wood jams $[8,9]$.

In this paper, we present a comparative field study of LW recruitment, mobility and deposition in two steep channels $(0.06<S<0.20)$ of contrast mountainous European landscapes during major hydro-geomorphic events of similar magnitude (assumed ca. 20y recurrence interval). We investigated a headwater perennial stream of the temperate climatic zone and a semi-arid Mediterranean channel. Both studied hydro-geomorphic events had in some parts of the channels the signs of debris-flood or debris-flow processes, which transported significant volumes of LW. We discuss the role of trees living in the valley corridor, which were crucial for the pattern of LW recruitment and storage at both sites.

\section{Studied sites and events}

\subsection{Central European perennial stream}

The Klepáčský is situated within the medium-high mountainous relief of the Hrubý Jeseník Mts., Eastern Sudetes, Czech Republic (50¹0'46.2"N; $\left.17^{\circ} 06^{\prime} 02.1^{\prime \prime E}\right)$. We studied a 1.70 $\mathrm{km}$ long headwater section of the stream with a beginning point roughly $400 \mathrm{~m}$ downstream from the spring area. The basin area was $0.2 \mathrm{~km}^{2}$ and $2.5 \mathrm{~km}^{2}$ at the upstream and downstream ends of the studied section, respectively. Channel slope generally corresponded to the value of $0.10 \mathrm{~m} / \mathrm{m}$ in the relatively unconfined reaches downstream, and increases up to $0.20-0.25 \mathrm{~m} / \mathrm{m}$ in the upstream segments. Twelve check dams were constructed in the $1960 \mathrm{~s}$ in the studied section to stabilise the stream longitudinal profile and to decrease bedload transport rates. They are presently at various stages of destruction having the average present-day height $1.5 \mathrm{~m}$ when compared to an average height of $2.5 \mathrm{~m}$ after their construction in the 1960s. A significant change of the forest cover has been manifested during the last 20 years in the upstream section. Several wind breakages that first appeared between 2000 and 2003 were more widespread after a strong windstorm in 2007. These events led to an increased recruitment of LW to the channel throughout this newly open area during subsequent years. The forest in the basin is consisted mainly of Norway spruce (Picea abies (L.) Karst.), which is supplemented by European beech (Fagus sylvatica L.). As observed in neighbouring Carpathian mountains, such forest composition indicates potential residence time of LW in headwater streams up to 60 years for beech pieces and up to 100-150 years for spruce logs [10].

. We examined the aftermaths of the debris-flow event triggered by severe rainstorm in May 2010 (76.5 mm/6h at the mountain summits). This process caused the depletion and transport of a substantial amount of LW including LW recruited by windthrows from the upper part of the basin to the downstream area, where the LW pieces were deposited and redistributed. The transport of sediments and LW continued downstream most likely as a debris flood with respect to the different channel and valley morphology and lower channel gradient. Based on the analysis of historical records (post-event photographs and project documentations of forest management authorities) as well as the results of dendrogeomorphic dating [11], similar high-magnitude hydro-geomorphic events occurred four times during the twentieth century (1903,1921, 1965, and 1991), suggesting their return period of ca. $20-30$ years. 


\subsection{Medditeranean ephemeral stream}

We examined a $4.05 \mathrm{~km}$ long unmanaged reach of the Sfakiano Gorge valley floor, with the basin area of $46.9 \mathrm{~km}^{2}$ and $51.3 \mathrm{~km}^{2}$ at the upstream and downstream ends of the studied section, respectively. The studied stream drains out the southern slopes of the Lefka Ori Mts, Crete, Grece $\left(35^{\circ} 13^{\prime} 20^{\prime \prime} \mathrm{N} ; 2^{\circ} 09^{\prime} 04^{\prime \prime} \mathrm{E}\right)$. The valley floor width was strictly confined by very steep hillslopes $\left(>45^{\circ}\right)$ and rock cliffs, which resulted in high variation of the observed valley floor width (ca. 8-40 m) with relatively abrupt changes of this parameter along the studied stream. The valley slope slightly increases in the downstream direction (from $0.06 \mathrm{~m} / \mathrm{m}$ in the upper part to $0.12 \mathrm{~m} / \mathrm{m}$ by the end of studied profile) due to the high tectonic activity of the coastal fault zone [12]. The more or less continuous forest cover consisting of Mediterranean cypress (Cupressus sempervirens L.), Evergreen oak (Quercus ilex L.), Kermes oak (Quercus coccifera L.) and European olive (Olea europaea L.) occurred along the studied section, reflecting local, but strictly seasonal precipitation gradient $(200 \mathrm{~mm} /$ year near the coastline to more than $1000 \mathrm{~mm} /$ year in mid-mountain parts mostly falling between October and May) [13].

Some parts of the studied section were without the clear presence of an alluvial channel limited by banks, which suggests only weak or subsurface flow during winter storm seasons except for rare high-magnitude flood events. We focused on the last morphologically important flood event occurring in December 2000, which had most likely the character of debris flood along the major part of the studied section. Previous high-magnitude flood was observed in 1993 in this region. No other flood event of similar magnitude has taken place since 2000. By eye-witness of local people, smaller, frequent flow events triggered by common winter storms are usually not capable to produce notable morphological changes in the studied stream including transport of LW.

\section{Methods}

Slightly different field methods were used between the study sites with respect to their specifics, but all LW metrics and channel/valley geometry were continuously recorded for $50-\mathrm{m}$ stream segments. We used conventional criteria for minimal dimensions of LW pieces $(1 \mathrm{~m}$ in length and $0.1 \mathrm{~m}$ in diameter; [14]), when the total lengths of individual pieces ( $\pm 0.1 \mathrm{~m}$ accuracy) together with the diameters at either end $( \pm 0.01 \mathrm{~m}$ accuracy) were measured by a tape. In the Klepáčský, we measured all LW pieces presented in the active channel and we also included LW pieces stored upon the lowest surfaces of adjacent alluvial and debris-flow terrace deposits outside the active-channel margins, wherein we assumed that deposition occurred during the last high-magnitude event in 2010 (as was also documented by a limited number of post-event photos taken by local forest managers). All large jams ( $\geq 10 \mathrm{LW}$ pieces) were formed by transported LW during the 2010 event, which, in turn, represented the minimal estimation of transported LW volume by this event. The age of the development of large jams was confirmed by cross-dating of $55 \mathrm{LW}$ pieces stored along the channel: (i) no cross-dated LW stored in jams died after 2010 , (ii) $70 \%$ of cross-dated LW died between 2002-2010 as the result of preceding windstorms and 2010 flood event, and (iii) no flood event of similar or larger magnitude occurred in the study area in the period 1992-2016 [15].

In the Sfakiano, we measured all LW pieces presented in the active valley floor, where we distinguished individual LW pieces between previously transported (clustered LW pieces, LW composed in lobate valley-floor deposits or LW pieces racked by boulders or living trees) and non-transported. We defined the 'active valley floor' as the lowermost part of the relatively flat valley floor, where we found LW pieces and gravels clearly deposited by last flood events and scars on living trees caused by the transport of wood or sediments 
during these events. In addition, the number of mature living tress in the valley floor was noted in the field. We tried to apply dendrochronological technique of cross-dating to assess LW residence time in this ephemeral stream, but we were unsuccessful due to the strong wood decay disrupting tree rings of the majority of LW pieces. However crossdating of scars on living trees with upstream LW deposition documented that these scars originated exclusively during the 2000 event [16]. Therefore, we assume that the majority of transported LW was mobilised by this event, although some limited transport of smaller wood pieces could occur also in following years in channelized segments of the studied stream.

\section{Results and discussion}

\subsection{Total large wood loadings and wood recruitment}

The studied streams indicated different total LW frequency and volumes in the part of the valley floor, which was affected by last high-magnitude hydro-geomorphic event (in the year of 2000 in the Sfakiano and 2010 in the Klepáčský). In the Klepáčský, we measured $934 \mathrm{LW}$ pieces along the $1.70-\mathrm{km}$-long examined section $(54.9 \mathrm{LW}$ pieces per $100 \mathrm{~m}$ channel length), with a total wood volume of $123 \mathrm{~m}^{3}\left(7.23 \mathrm{~m}^{3}\right.$ per $100 \mathrm{~m}$ channel length). Much lower LW frequency was observed in the Sfakiano $(19.6 \mathrm{LW}$ pieces per $100 \mathrm{~m}$ channel length in $4.05-\mathrm{km}$-long reach), which made a total wood volume of $132 \mathrm{~m}^{2}$ $\left(3.26 \mathrm{~m}^{3}\right.$ per $100 \mathrm{~m}$ channel length) represented by 795 measured LW pieces.

These differences in LW abundance can be directly related to the different character of tree stands growing in the valley floor and at adjacent hillslopes as well as to specific recruitment processes at both sites. Higher biomass production characterised by dense forest stands was observed in the wetter Central European medium-high mountains, whereas rather sparse forest stands were typical for semi-arid Mediterranean climate. Moreover, the upper part of the Klepáčský was affected by preceding windstorms, which delivered a high number of LW pieces into the channel from adjacent hillslopes. The lateral erosion during the flood event with possible LW recruitment occurred only in some parts of the downstream reach under semi-confined/unconfined valley settings. We did not notice similar massive lateral supply of LW in the Sfakiano (e.g. by wildfires or windstorms), when only a few spatially-limited hillslope instabilities could affect lateral supply of LW. The majority of LW is recruited here directly from the active valley floor by tree throws, which most likely happens only during high-magnitude flood events similar to the 2000 event. Although some previous studies suggested slow decay rates of wood in semi-arid conditions $[17,18]$, we observed relatively fast decay processes in the Sfakiano most likely due to biotic agents (wood-destroying insects). Therefore we were not able to successfully apply cross-dating methods to estimate residence time or the year of LW recruitment in this ephemeral stream.

\subsection{Large wood transport and deposition during high-magnitude events}

We found signs of LW redistribution in both studied streams related to the last highmagnitude events. These redistributions were often represented by the presence of large log jams as the clustering of LW pieces is perceived as the typical artefact of wood transport and deposition. Based on the measurements of large jams ( $\geq 10$ LW pieces) in the Klepáčský, we estimated the minimal transported volume during the 2010 event equal to $71.3 \mathrm{~m}^{3}$ (58\% of the total measured wood load). The obtained values corresponded to transport LW rates of $41.9 \mathrm{~m}^{3} \mathrm{~km}^{-1}$ per stream length or $28.5 \mathrm{~m}^{3} \mathrm{~km}^{-2}$ per basin area. These 
values fell well into the power relationship between the exported LW volumes (by both floods and debris flows) and basin areas during the large flood event in the much steeper environment of Swiss Alps (50-300 year recurrence interval) [3].

The frequency of large jams declined in the downstream direction while the majority of wood was stored in the depositional zone of debris flow in the upper semi-confined part of the studied stream (ca. 0.1-0.6 km; Fig. 1). Notably lower volume of LW was deposited downstream by the debris flood. Except the channel and valley morphology, the living trees in the valley floor played important role in LW out-of-channel retention during the event along the entire longitudinal course (Fig. 2a), A few large jams developed also in the sedimentary wedges of damaged check dams (Fig. 2b). The LW storage by check dams (including individual, non-clustered LW pieces) reached ca. $25 \%$ of the total LW volume $\left(30.5 \mathrm{~m}^{3}\right)$.

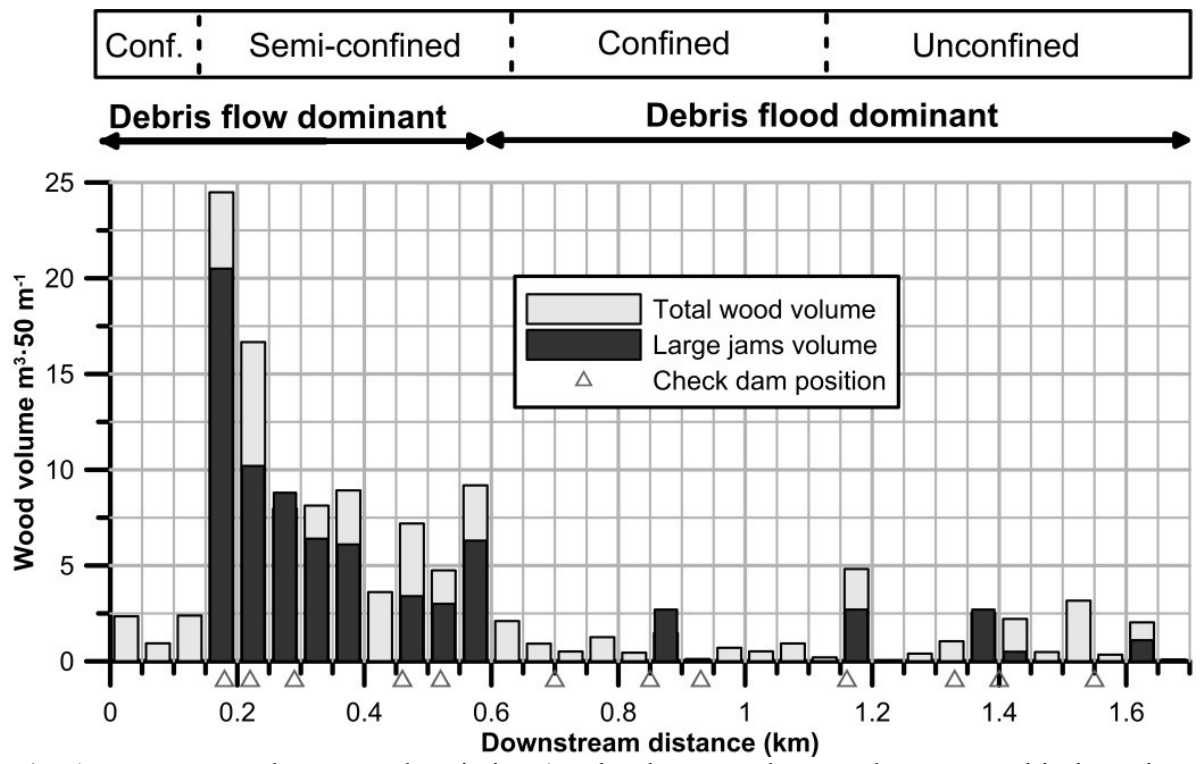

Fig. 1. Downstream large wood variation (total volumes and LW volumes stored in large jams which developed during the 2010 event) in the Klepáčský. The valley confinement, dominant process during the 2010 event and the positions of damaged check dams are indicated. 

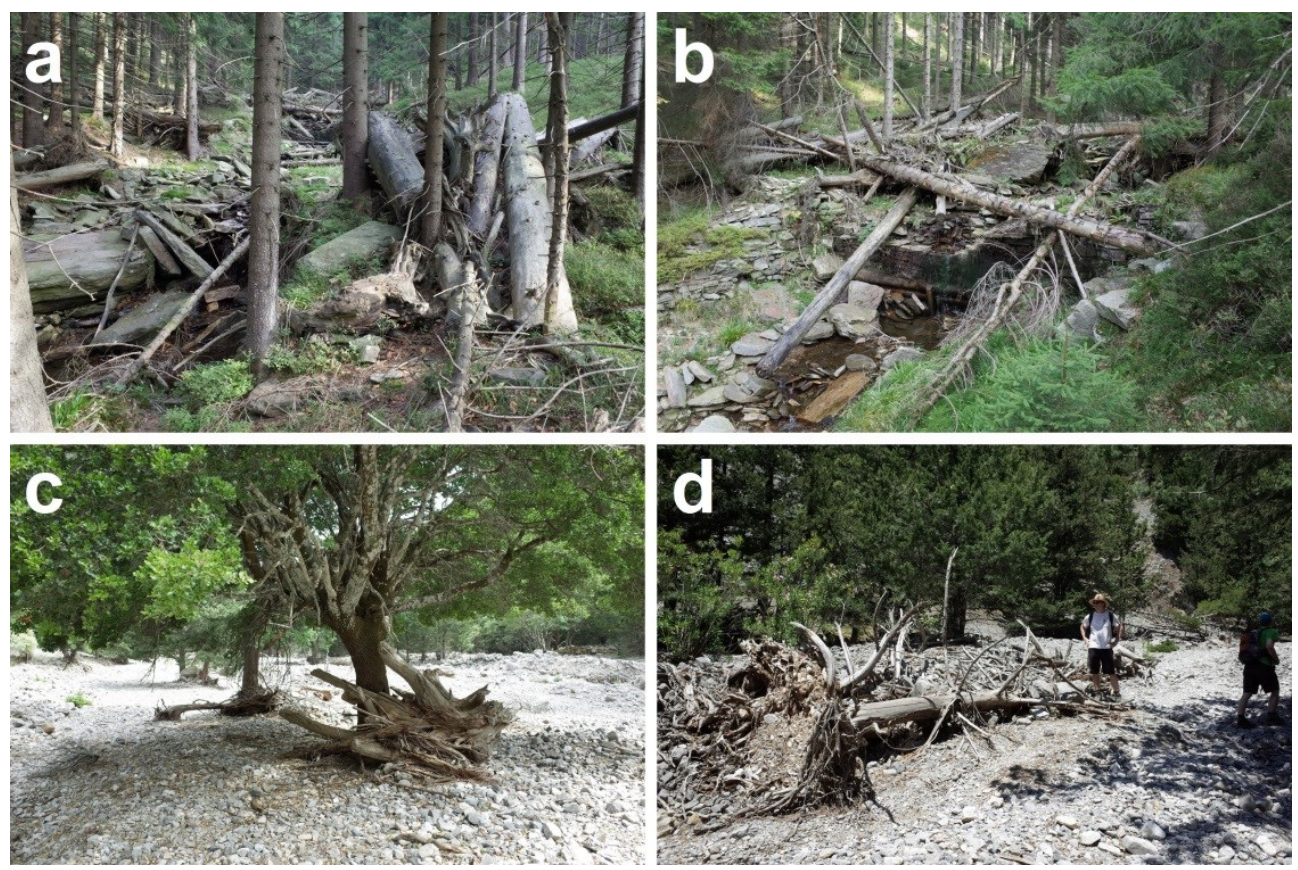

Fig. 2. Living trees (a) and a damaged check dam (b) initiating development of large jams during the 2010 event in the Klepáčský. Living trees trapping transported LW after the 2000 event (c) and individual transported LW piece with partially preserved root wad (d) in the Sfakiano.

The living mature trees in the relatively wide valley floor act as flow obstructions and they were responsible for the development of log jams during the high-magnitude event in the ephemeral Mediterranean channel (Fig. 2c). In contrast to the Klepáčský, the longitudinal distribution of jams was highly variable and in general, more jams were developed in the middle part of the studied section with the widest active valley floor and a high number of living trees (Fig. 3). The volume of LW clustered in these jams was $20.7 \mathrm{~m}^{3}$ (16\% of the total wood load). We determined additional $28.7 \mathrm{~m}^{3}$ of LW including tree throws with almost complete root wads, which indicated signs of previous mobility (e.g., partial burying in lobate deposits, racking by living trees or boulders) (Fig. 2d). It implies that most of $49.4 \mathrm{~m}^{3}$ volume of transported wood $(37.4 \%$ of the total wood load measured in the stream) was redistributed during the last high-magnitude flood in 2000. Due to fast decay processes of dead wood, we do not assume preservation of considerable number of LW pieces deposited by previous large flood in 1993. By contrary, only a limited number of small wood pieces could be mobilised in the channelized sections of the stream by common flow events triggered by winter storms. Considerably more intensive LW transport along the entire longitudinal stream profile occurred in 2000 as revealed from the dating of scars on living trees with upstream deposited LW jams. 


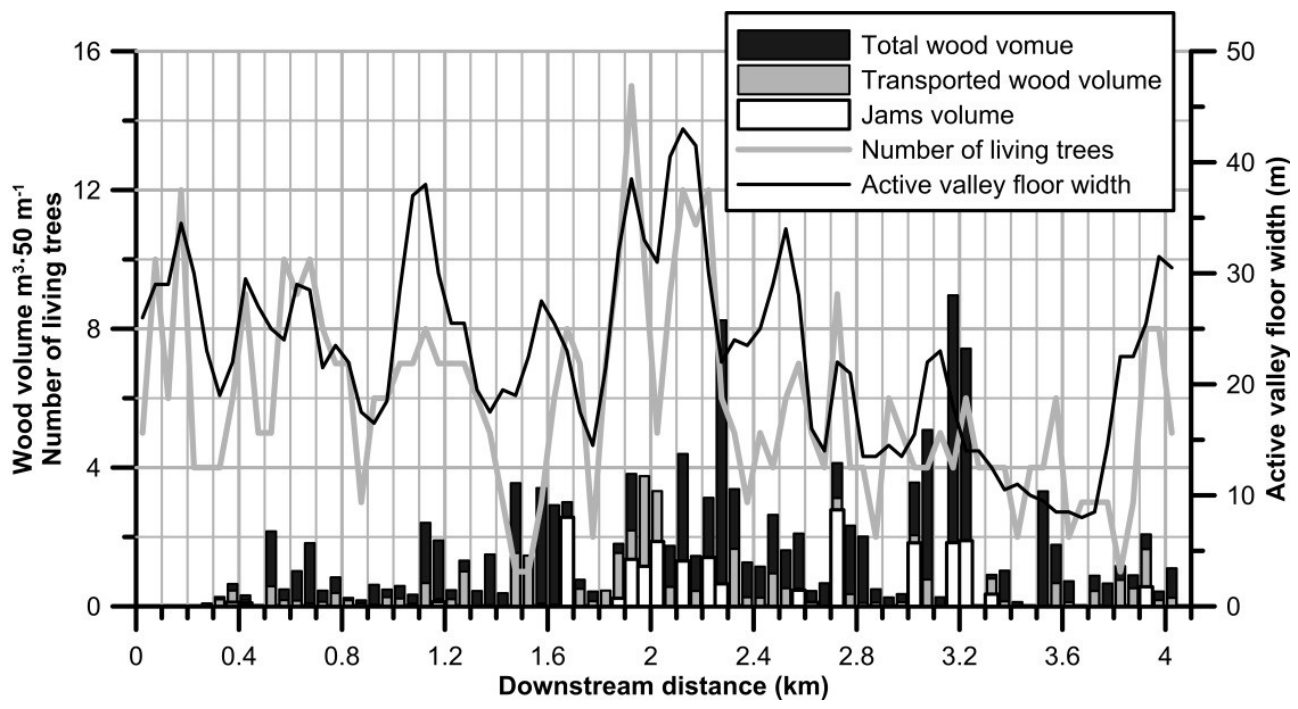

Fig. 3. Downstream large wood variation (total LW volume, transported LW volume and LW volume stored in jams) in the Sfakiano. The active valley floor width and the number of mature living trees in the valley floor are indicated.

\section{Conclusions}

Major flood events triggering debris flows/debris floods caused considerable redistribution of LW pieces in both studied environments. We were even able to observe notable signs of LW transport during the high-magnitude hydro-geomorphic event after more than 15 years in the case of the Sfakiano. Despite the differences in the valley morphology and the character of tree vegetation, living trees in the valley floor played important role in LW deposition during these events. Additionally, these living trees were also the main recruitment sources of LW for the studied Mediterranean stream due to relative stable adjacent hillslopes and lacks of other recruitment processes (e.g., windstorms, wildfires) in the basin. In the case of Central European perennial stream, previous windstorms were perceived as dominant recruitment agent, which directly affected subsequent volumes of mobilised wood during the large hydro-geomorphic event in 2010.

In mountainous landscapes, intensive LW transport during extraordinary hydrogeomorphic events can represent a serious hazard for developing tourist infrastructure. However quantitative field data of the LW mobility during these events (including both debris flows and floods) in steep streams are missing from the majority of forested mountainous ranges. Therefore we call for the future research and monitoring of LW transport not only in large rivers surrounded by densely inhabited floodplains but also in steep streams to fill the gap in knowledge regarding (i) total transported LW volumes by particular event and (ii) geometrical parameters of transported LW pieces in relation to channel geometry or dominant transport process.

The study was supported by SGS05/PřF/2017-2018. The authors would like to thank to Karel Šilhán for his help during the field works. 


\section{References}

1. A. Lucía, F. Comiti, M. Borga, M. Cavalli, L. Marchi, Nat. Hazards Earth Syst. Sci. 15, 1741-1755 (2015)

2. F. Comiti, A. Lucía, D. Rickenmann, Geomorphology 269, 23-39 (2016)

3. N. Steeb, D. Rickenmann, A. Badoux, C. Rickli, P. Waldner, Geomorphology 279, 112-127 (2017)

4. V. Ruiz-Villanueva, H. Piégay, A.M. Gurnell, R.A. Marston, M. Stoffel, Rev. Geophys. 54, 611-652 (2016)

5. N. Kramer, E. Wohl, Geomorphology 279, 74-97 (2017)

6. M.A. Hassan, D. Hogan, S.A. Bird, C.L. May, T. Gomi, D. Campbel, J. Am. Water Resour. Assoc. 41, 899-919 (2005)

7. B., Wyżga, J. Zawiejska, P. Mikuś, R.J. Kaczka, Geomorphology 228, 275-285 (2015)

8. C.L. May, R.E. Gresswell, Earth Surf. Process. Landf. 28, 409-424 (2003)

9. L. Benda, M.A. Hassan, M. Church, C.L. May, J. Am. Water Resour. Assoc. 41, 835$851(2005)$

10. T. Galia, K. Šilhán, V. Ruiz-Villanueva, R. Tichavský, M. Stoffel, Geomorphology 292, 35-46 (2017)

11. R. Tichavský, K. Šilhán, R. Tolasz, Sci. Total Environ. 579, 1904-1917 (2017)

12. R.J.J. Pope, I. Candy, E. Skourtsos, Quat. Res. (United States) 86, 170-183 (2016)

13. O. Rackham, J. Moody, The making of the Cretan Landscape (Manchester University Press, Manchester, 1996)

14. E. Wohl. D.A. Cenderelli, K.A. Dwire, S.E. Ryan-Burkett, M.K. Young, K.D. Fausch, Earth Surf. Process. Landf. 35, 618-525 (2010)

15. T. Galia, R. Tichavský, V. Škarpich, K. Šilhán, Catena 165, 537-550 (2018)

16. T. Galia, V. Škarpich, R. Tichavský, L. Vardakas, K. Šilhán, Geomorphology 310, 15 28 (2018)

17. D.C. Andersen, C.A. Stricker, S.M. Nelson, For. Ecol. Manage. 365, 83-95 (2016)

18. K.B. Lininger, E. Wohl, N.A. Sutfin, J.R. Rose, Earth Surf. Process. Landf. 42, 12481261 (2017) 